Krzewski Szymon, Baranowski Mateusz, Zubrzycki Robert, Stachurski Maciej, Borowicz Janusz. Correlation between temporomandibular joint dysfunction and Eichner classification. Journal of Education, Health and Sport. 2020;10(4):155-162. eISSN 2391-8306. DOI http://dx.doi.org/10.12775/JEHS.2020.10.04.017

https://apcz.umk.pl/czasopisma/index.php/JEHS/article/view/JEHS.2020.10.04.017

https://zenodo.org/record/3760173

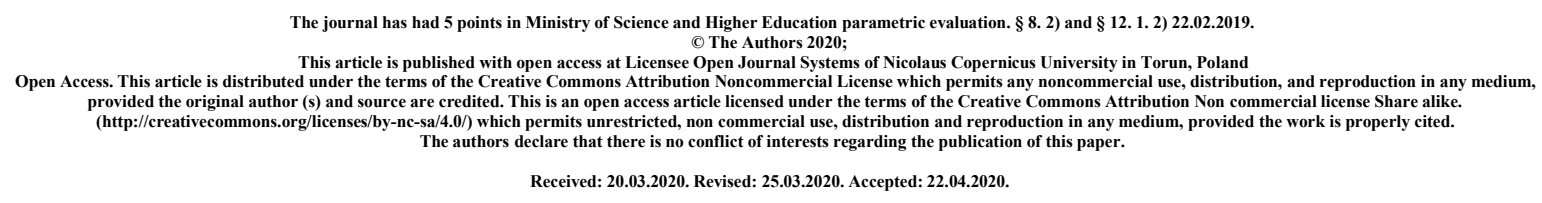

\title{
Correlation between temporomandibular joint dysfunction and Eichner classification
}

\section{Szymon Krzewski, Mateusz Baranowski, Robert Zubrzycki, Maciej Stachurski, Janusz Borowicz}

Szymon Krzewski 1 - https://orcid.org/0000-0003-2339-6741 smn.krzak@gmail.com Mateusz Baranowski 2* - https://orcid.org/0000-0001-7266-738X

mateusz.gromek.baranowskI@gmail.com

Robert Zubrzycki 3 - https://orcid.org/0000-0001-6932-6381

robertzub92@gmail.com

Maciej Stachurski 4 - https://orcid.org/0000-0001-6872-0694

mmaciejstachurski@gmail.com

Janusz Borowicz 5 - https://orcid.org/0000-0002-6567-2604 janusz.borowicz@umlub.pl

1.lek. dent., Chair and Department of Pedodontics, Medical University of Lublin, Poland

2. lek. dent., Chair and Department of Periodontology Medical University of Lublin

3. lek. dent., Department of Dental Prosthetics, Medical University of Lublin, Poland

4. lek. dent., Department of Dental Prosthetics, Medical University of Lublin, Poland

5. dr hab. n. med., Department of Dental Prosthetics, Medical University of Lublin, Poland 


\title{
*Corresponding Author:
}

Mateusz Baranowski - PhD student, dentist mateusz.gromek.baranowski@gmail.com

Chair and Department of Periodontology Medical University of Lublin, Poland

\author{
Abstract characters:2920 \\ Abstract word count: 456 \\ Word count: 1704 \\ Number of Tables: 1 \\ Number of Figures: 2
}

Key words: temporomandibular joint, dysfunction, Eichner classification, prosthetics, dentures.

\section{Abstract \\ Introduction:}

The Dental Prosthetics Department's most common patients are elderly who have lost their teeth. Dental deficiencies not only impair the functions of the stomatognathic system but can also be the cause of temporomandibular disorders (TMD). Deficiencies in the lateral sections lead to a decrease in the occlusion height in patients, which negatively affects the aesthetics of the face by shortening the lower floor and overloading the remaining teeth, eventually leading to their pathological wear. Loss of occlusion height changes the spatial arrangement of the lower jaw to the upper jaw, which can lead to changes in the temporomandibular joint. The loss of a tooth or group of teeth is an indication for proper prosthetic treatment. The dentist should be able to take into account, evaluate and, if necessary, cure TMD, but this is not a common skill among dentists. Such treatment requires an appropriate comprehensive approach. There are currently no standards for such treatment. We presented one of the methods as part of our study.

\section{Purpose of work:}

The aim of the study was to check the correlation between the occurrence of temporomandibular disorders and missing teeth and used prosthetic restorations.

\section{Material and methods:}

Medical history records of 58 patients under the care of the Department of Dental Prosthetics at Medical University of Lublin were analyzed. Factors such as age and gender, occlusion height, distribution of missing teeth according to the Eichner classification and symptoms of temporomandibular joint disorders, i.e. crackling, pain, limited and excessive abduction of the jaw were checked.

Before starting prosthetic treatment, every patient underwent comprehensive conservative, surgical and periodontics treatment in accordance with existing needs. 


\section{Results:}

The study group consisted of 38 women and 20 men. The average age of all patients was 69.6 years; - average for men - 70.45 years, women 68.16 years. The oldest patient was an 88 -yearold man, and the youngest was a 43 -year-old woman. $31 \%$ of patients were toothless. $25.9 \%$ of patients had pain within the stomatognathic system, of which $86.7 \%$ were women and $13.3 \%$ men. Relaxation splint was made in $24.1 \%$ of patients.

\section{Summary:}

The study showed that the ailments associated with the stomatognathic system are correlated with a reduction in occlusion height. Larger dental deficits are more common in older people. Pain symptoms are the most common cause of making relaxation splints. Women more often than men complain of pain. The correct treatment scheme for patients with missing teeth and long-term loss of support zones is staggered treatment - two-stage. The first stage of treatment is to restore the correct occlusion height by using the occlusal splint. Then, after the adaptation period, there is a transition to the second stage of treatment - the use of proper prosthetic restoration maintaining the correct height of occlusion.

\section{Article}

Temporomandibular joint temporomandibular joint (TMJ) is one of the most complex joints in the human body (1). Its complexity results, among other things, from the combination of the right and left joint with one jawbone, two joint levels and the presence of a removable disc. In addition, TMJ is a physiological one part with the teeth, muscles and nerves of the cranium forming a stomatognathic system. The complicated arrangement of these structures means that temporomandibular disorders may appear. Symptoms on the part of TMJ indicating Temporomandibular disorder (TMD) may be general pain, limited mouth opening, clatter, headache and blockage of the articular disc. (2-6) The etiology of TMD is multifactorial and it's very controversial issue in clinical dentistry.(7-9) Some authors classify TMD in a broader perspective, including in addition to typical symptoms such as osteoarthritis and muscle pain.(10,11) Problems with TMJ affect an average of 10 to $15 \%$ of adults, occurring more often among women especially in the 20-40 age group.(4)

Correct distribution of bite forces is essential for stability of TMJ $(4,5,7)$. Loss of stability caused by the lack of a tooth or group of teeth can act as a predisposing, initiating or fixing factor for existing TMDs. Studies show that the loss of five or more teeth and toothlessness can be associated with the discomfort and severity of TMD. (7) The role of the presence of prostheses in people suffering from TMD is still the subject of numerous discussions and is not finally resolved.(10,12) Studies show that people using dental prostheses are more likely to suffer from TMD-related complaints compared to people with full dental arches.(10) However, some authors of the publication believe that missing teeth and lack of support zones in the lateral sections have a small, marginal effect on the occurrence of TMD.(8) The multifactorial etiology of TMD shows that even the most severe occlusal disturbances do not necessarily lead to functional disorders. $(8,13)$. Eichner's classification was used to investigate the relationship between missing teeth and TMD in patients of the Dental Medical Center. 
In order to assess the extent of missing teeth and loss of occlusal support zones, the Eichner classification was used. We can distinguish there 3 groups marked with letters "A", "B" and "C",

\begin{tabular}{|c|c|c|c|}
\hline \multirow[b]{2}{*}{$\begin{array}{c}\text { Eichner } \\
\text { classification }\end{array}$} & Group A & Group B & Group C \\
\hline & $\begin{array}{l}\text { (Occlusal contact in } \\
\text { all the support zones }\end{array}$ & $\begin{array}{l}\text { (Occlusal contact in } \\
\text { a few support zones) }\end{array}$ & $\begin{array}{l}\text { (Lack of occlusal } \\
\text { contact in any } \\
\text { support zones) }\end{array}$ \\
\hline Subgroup 1. & $\begin{array}{c}\text { A1 } \\
\text { the jaw and the } \\
\text { mandible truly } \\
\text { toothed, single } \\
\text { damaged, but again } \\
\text { rebuilt teeth }\end{array}$ & $\begin{array}{c}\text { B1 } \\
\text { occlusion is } \\
\text { appearing in } 3 \text { zones } \\
\text { of the support }\end{array}$ & $\begin{array}{l}\text { C1 } \\
\text { residual teeth of the } \\
\text { jaw and mandibles } \\
\text { without mutual } \\
\text { contacts }\end{array}$ \\
\hline Subgroup 2. & $\begin{array}{c}\text { A2 } \\
\text { one dental arch } \\
\text { without gaps, } \\
\text { opposing arch with } \\
\text { interdental gaps }\end{array}$ & $\begin{array}{c}\text { B2 } \\
\text { occlusion is } \\
\text { appearing in } 2 \text { zones } \\
\text { of the support }\end{array}$ & $\begin{array}{c}\text { C2 } \\
\text { one of the arch } \\
\text { toothless, second } \\
\text { toothed, }\end{array}$ \\
\hline Subgroup 3. & $\begin{array}{c}\text { A3 } \\
\text { gaps are appearing } \\
\text { in both dental } \\
\text { arches, however } \\
\text { propping is } \\
\text { appearing in all four } \\
\text { zones of the support }\end{array}$ & $\begin{array}{c}\text { B3 } \\
\text { occlusion is } \\
\text { appearing in } 1 \text { zones } \\
\text { of the support }\end{array}$ & $\begin{array}{c}\text { C3 } \\
\text { complete } \\
\text { toothlessness }\end{array}$ \\
\hline Subgroup 4. & $\mathbf{X}$ & $\begin{array}{c}\text { B4 } \\
\text { occlusion is } \\
\text { appearing outside } \\
\text { zones of the support }\end{array}$ & $\mathbf{X}$ \\
\hline
\end{tabular}

Tab. nr.1 - classification of Eichner, Protetyka Stomatologiczna prof. E. Spiechowicz PZWL Warszawa 2013, wyd.6.

Theoretically, changes in the height of the occlusion should not be observed in group "A", but they can be disturbed eccentric movements. In group "B" the changes can disturb both eccentric movements and the distribution of chewing forces, and in group " $\mathrm{C}$ " it should be expected a change in the resting height of the lower jaw, disorder or lack of any guidance and a tendency to protrusive movement of the lower jaw. 
In the tests, the missing teeth were distributed as follows:

\section{Distribution of individual types of missing teeth according to the Eichner classification}

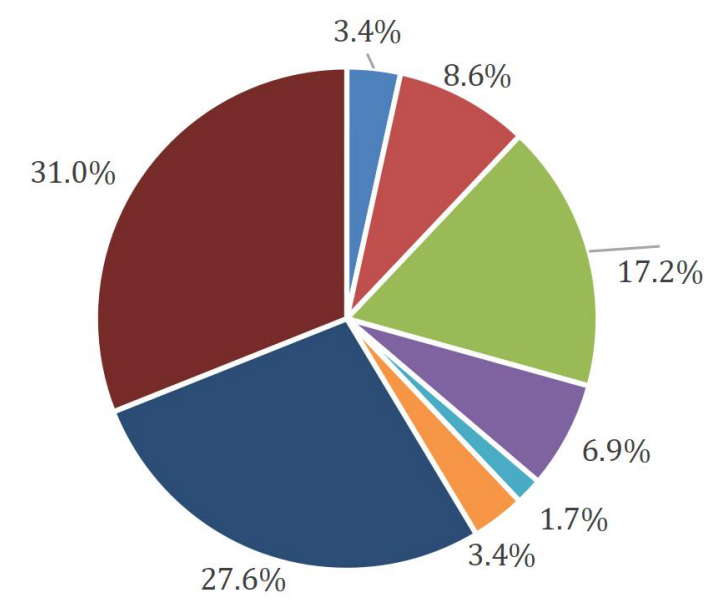

\section{A3 \\ B1 B2 \\ B3 B4 \\ C1 \\ C2 \\ C3}

Ryc.1 Distribution of individual types of missing teeth according to the Eichner classification The highest number of completely edentulous patients - C3 - was recorded, which constituted as much as $31 \%$ of all examined patients. The second most numerous groups were patients with A3 deficiencies, who constituted $27.6 \%$ of the respondents. In the literature, research on TMD in people using prosthetic restorations is not a frequently discussed topic.(10)

The occurrence of TMD in toothless people varies, depending on the conducted research, from values close to zero to values higher than in people with full dental arches.(13) Wilding \& Owen research from 1987 shows that among toothless people only 5\% of patients without prosthetic restorations suffered from mild symptoms of TMD, and none of the patients had severe TMD. (13) Research conducted on the Department of Dental Prosthetics showed that among the treated toothless people, 3\% of patients suffered from pain, all had prosthetic treatment recommended. Research from Finland shows that toothlessness, the use of full dentures and poor condition of the denture correlate with TMJ pain and muscle pain. $(10,11)$ This tendency is visible mainly in women. According to the authors, it is probably correlated with less bone, earlier tooth loss and greater loss of bone processes. (10) In addition, the longer the prosthetic restorations are used, the greater the chance for TMD to occur. $(10,12)$ Women start using prostheses earlier and, on average, live longer than men. It follows that they use dentures for a longer time. In addition, it is especially in women that the total lack of dentition correlates more strongly with TMD than partial deficiencies. (10) For toothless, the complete absence of prosthetic restorations for a long time is conducive to shifting the position of the mandible to the jaw in the horizontal and vertical planes. As a result, the position of the condyles may change, which may be one of the factors initiating TMD. (9) 
Pain associated with TMD cannot be characterized unambiguously. May produce similar symptoms as neurogenic, psychogenic, visceral, skin, tooth or periodontal pain. (9) The Department of Dental Prosthetics research showed that $25.9 \%$ of patients had pain within the stomatognathic system, of which $86.7 \%$ affected women and $13.3 \%$ men. Various epidemiological studies have shown that at least $33 \%$ of the general population may experience TMJ pain symptoms. (14) Thomas List in the review of research on pain confirms the more frequent occurrence of this ailment in women. (4). There is no clear evidence in the literature that all TMD sufferers should be treated with prosthetic restorations. Performed prosthetic treatment often leads to pain relief and normalization of TMJ function(13). In the study, none of the people using prosthetic restorations reported symptoms from TMJ. Pain only accompanied people who did not use any prostheses. All people with pain were qualified for the treatment.

Among TMD patients, blockage of the disc in TMJ is not a rare symptom. $(13,15)$ Displacement of the disc is observed in $30 \%$ of healthy adults and $10 \%$ of teenagers.(4) Clicking of the disc often accompanies TMD, and the sound itself changes over time. (13) Both in the Department of Dental Prosthetics, as well as in the research of other authors, this problem was more common in women $(10,15,16)$

Cracks in the temporomandibular joint were found in 5.2\% of patients, of which:

- $66.7 \%$ had A3 deficiencies according to Eichner

- 33\% had type B1 deficiencies Eichner

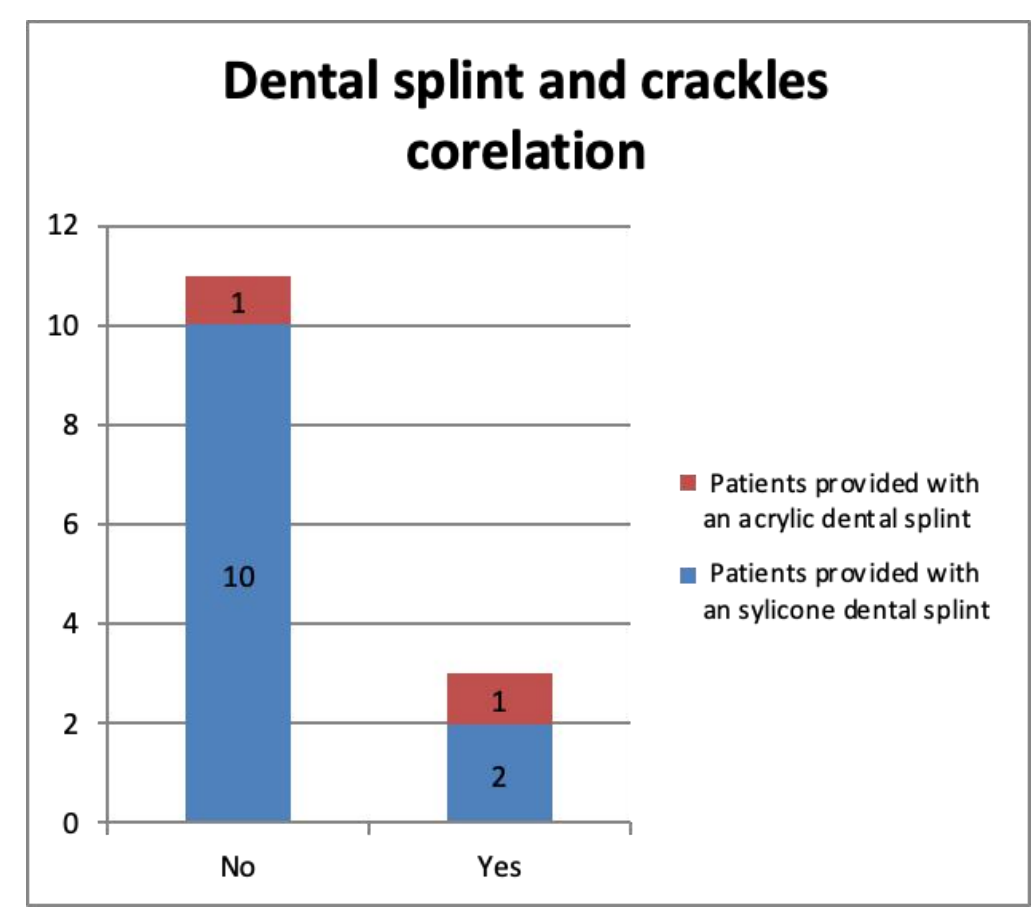

Ryc.2 Dental splint and crackles correlation

$74.14 \%$ of people with crackling do not suffer from the stomatognathic system. Only in $25.86 \%$ of the examined patients, together with reported pain, were clicks in the temporomandibular joint. Among all subjects, only two patients had a problem with limited 
mandibular abduction, and one of them reported an episode of blockage of the disc in the temporomandibular joint.

In the conducted study, among patients with prosthetic treatment recommendations, in $30 \%$ of people, it was first decided to perform non-invasive treatment - relaxation splint, $85.7 \%$ of them reported pain before treatment. The use of treatment including relaxation splint, on Department of Dental Prosthetics, has significantly led to a reduction in pain over time. Is this treatment the most appropriate? Especially, including the fact, relaxation splints are not used to fulfill missing teeth? It seems not. In the extensive study leaded by the British National Institute for Health Research there was compared the effectiveness of the use of relaxation splints, compared to the effectiveness of non-invasive muscle relaxation exercises combined with patient education and elements of psychotherapy. In this study, relaxation splints were the optimal solution only in $29 \%$ of cases.

\section{Conclusion:}

Relaxation splints are often overused, although they can be helpful, especially when the alternative is expensive occlusion remodeling. However, they do not show any advantage over relaxation methods using physiotherapy and psychology. In the case of patients completely toothed or with slight dental deficiencies, treatment should be started noninvasively (education, relaxation, physiotherapy), then, optionally use splints, and then as a last resort movable or, finally, permanent prosthetic restorations. This is the right approach that will improve chewing function and aesthetics, and may help to reduce TMD by minimizing potential disadvantage (17)

For patients partially or completely edentulous with TMD, the treatment procedure must include restoration of missing teeth. The optimal treatment procedure for patients with longterm loss of support zones seems to be two-stage treatment. The first stage of treatment consists in restoring the correct occlusion height by using the occlusal splint or overlay splint methods. The second stage of treatment is the use of appropriate prosthetic restoration maintaining the correct height of occlusion. Depending on the loss of occlusion height, it is advisable to stretch duration of prosthetic treatment. The presence of TMD disorders is related to the age and time of the use the prosthesis and increases in old age. By. The Central Statistical Office of Poland (CSO), data for 2019, the average citizen is 41 years old, and the average life expectancy is 81.7 for women and 73.8 for men, respectively. It can therefore be assumed that in an aging society, the need for prosthetic treatment as well as TMD will become ever greater. Unfortunately, there are no TMD treatment standards, and the attempt to evaluate the studies is unclear. A promising alternative in the treatment of pain patients are forms of treatment taking place outside the dental office, such as: behavioral therapy, biofeedback, behavioral-cognitive therapy, acupuncture or developing habits. Techniques for relaxing and strengthening the TMJ muscles also bring beneficial results. Multifactorial TMD requires above all a comprehensive approach to the patient taking into account not only dental factors. 


\section{Bibliography:}

1. Zhou ZH, Chen XZ, Chen XW, Wang YX, Zhang SY, Sun SF, i in. Improved anchoring nails: design and analysis of resistance ability: Tensile test and finite element analysis (FEA) of improved anchoring nails used in temporomandibular joint (TMJ) disc anchor. BMC Oral Health. grudzień 2018;18(1):150.

2. Ferreira MC, Porto de Toledo I, Dutra KL, Stefani FM, Porporatti AL, Flores-Mir C, i in. Association between chewing dysfunctions and temporomandibular disorders: A systematic review. J Oral Rehabil. październik 2018;45(10):819-35.

3. Al-Moraissi EA, Wolford LM, Perez D, Laskin DM, Ellis E. Does Orthognathic Surgery Cause or Cure Temporomandibular Disorders? A Systematic Review and Meta-Analysis. J Oral Maxillofac Surg. wrzesień 2017;75(9):1835-47.

4. List T, Jensen RH. Temporomandibular disorders: Old ideas and new concepts. Cephalalgia. czerwiec 2017;37(7):692-704.

5. Clark GT, Tsukiyama Y, Baba K, Watanabe T. Sixty-eight years of experimental occlusal interference studies: What have we learned? J Prosthet Dent. grudzień 1999;82(6):704-13.

6. Todic J, Martinovic B, Pavlovic J, Tabakovic S, Staletovic M. Assessment of the impact of temporomandibular disorders on maximum bite force. Biomed Pap. 23 wrzesień 2019;163(3):274-8.

7. Sousa ST de, Mello VVC de, Magalhães BG, Morais MPL de A, Vasconcelos MMVB, Junior A de FC, $\mathrm{i}$ in. The role of occlusal factors on the occurrence of temporomandibular disorders. CRANIO®. lipiec 2015;33(3):211-6.

8. Boever JAD, Carlsson GE, Klineberg IJ. Need for occlusal therapy and prosthodontic treatment in the management of temporomandibular disorders. Part I. Occlusal interferences and occlusal adjustment. J Oral Rehabil. 2000;27(5):367-79.

9. Alzarea BK. Temporomandibular Disorders (TMD) in Edentulous Patients: A Review and Proposed Classification (Dr. Bader's Classification). J Clin Diagn Res JCDR. kwiecień 2015;9(4):ZE06-9.

10. Sipilä K, Näpänkangas R, Könönen M, Alanen P, Suominen AL. The role of dental loss and denture status on clinical signs of temporomandibular disorders. J Oral Rehabil. styczeń 2013;40(1):15-23.

11. Edwin A, Singh AM, Joseph AM. 2. TMD diagnosis and management - "a nightmare" or "is it really so". : 1 .

12. Manfredini D, Poggio CE. Prosthodontic planning in patients with temporomandibular disorders and/or bruxism: A systematic review. J Prosthet Dent. maj 2017;117(5):606-13.

13. De Boever JA, Carlsson GE, Klineberg IJ. Need for occlusal therapy and prosthodontic treatment in the management of temporomandibular disorders. $\mathrm{J}$ Oral Rehabil. sierpień 2000;27(8):647-59.

14. Carrara SV, Conti PCR, Barbosa JS. Statement of the 1st Consensus on Temporomandibular Disorders and Orofacial Pain. :7.

15. Bueno CH, Pereira DD, Pattussi MP, Grossi PK, Grossi ML. Gender differences in temporomandibular disorders in adult populational studies: A systematic review and meta-analysis. $\mathrm{J}$ Oral Rehabil. wrzesień 2018;45(9):720-9.

16. Gleissner C. Welchen Einfluss hat das Geschlecht auf die Mundgesundheit? Bundesgesundheitsblatt - Gesundheitsforschung - Gesundheitsschutz. wrzesień 2014;57(9):1099-106.

17. Riley P, Glenny A-M, Worthington HV, Jacobsen E, Robertson C, Durham J, i in. Oral splints for patients with temporomandibular disorders or bruxism: a systematic review and economic evaluation [Internet]. NIHR Journals Library; 2020 [cytowane 16 kwiecień 2020]. Dostępne na: https://www.ncbi.nlm.nih.gov/books/NBK553659/ 